\title{
A GOALS/QUESTIONS/METRICS PLAN FOR MONITORING USER INVOLVEMENT AND PARTICIPATION IN ERP IMPLEMENTATION PROJECTS
}

IE Working Paper

SI8-110-I

03-11-2004

José Esteves

Joan Pastor

Joseph Casanovas

Instituto de Empresa

Madrid, Spain

Jose.Esteves@ie.edu
Universidad Internacional. de Catalunya

Barcelona, Spain

jap@,unica.edu
Universidad Politécnica de Catalunya

Barcelona, Spain

josepk@fib.upc.es

\begin{abstract}
ERP implementation success is influenced by a large number of factors, which most of the times are difficult to measure objectively. User involvement and participation is one of the most cited critical success factors in ERP implementation projects, and one of the most critical ones for their satisfactory outcome. This study attempts to define a set of metrics for monitoring user involvement and participation within ERP implementation projects by using the Goals/Questions/Metrics method. The results of this work are threefold. First, a literature review is presented on the user involvement and participation topic as related with ERP implementation projects. Second, a framework for monitoring user involvement and participation in ERP implementation projects is proposed. And third, a Goals/Questions/Metrics preliminary plan is proposed to monitor and control user involvement and participation within ERP implementation projects.
\end{abstract}

\section{Keywords}

ERP implementation, User involvement and participation, Metrics, Goals/Questions/Metrics. 



\section{INTRODUCTION}

ERP project success is influenced by a large number of factors, and most of the times it is difficult to measure them objectively. Usually, the metrics proposed within ERP implementation methodologies are related with milestones and costs aspects. This is particularly due to the fact that these methodologies follow the common definition of project success: basically to be full functionality delivered on time and on budget. User involvement and participation is one of the most cited Critical Success Factors (CSFs) in ERP implementation projects (e.g. Bancroft et al. 1998, Bingi et al. 1999, Esteves and Pastor 2000, Kale 2000, Nah et al. 2001, Kawalek and Wood-Harper 2002). User involvement and participation results in a better fit of user requirements achieving better system quality, use and acceptance (Esteves and Pastor 2000). The terms 'user involvement' and 'user participation' have been commonly used interchangeably in the Information Systems (IS) literature (Barki and Hartwick 1994), but they are not the same and here we attempt to clarify both concepts. Kappelman and McLean (1991) hypothesized that IS success is indirectly influenced by user participation and mediated by user involvement. The most accepted model of user involvement, user participation and system use was developed and tested by Barki and Hartwick (1994, 2001). This study attempts to provide a set of metrics to help control and monitor user involvement and participation in ERP implementation projects in order to help managers achieve success in their projects. The derived set of metrics is the initial one from which particular ERP implementation may start its own specialized set. According to Jurison $(1999$, p. 28$)$ the purpose of project control is: "to keep the project on course and as close to the plan as possible, to identify problems before they happen and, implement recovery plans before unrecoverable damage is done". We noted that the extensive literature on user involvement and participation is related to software development. Thus there is the need to adapt previous works, to ERP implementation projects which have their own characteristics and lifecycle. As a result of this study, we are interested in a combined set of metrics to help managers understand the situation of the ERP implementation project. We have used the Goals/Question/Metric (GQM) method to develop this set metrics. The result of the application of this method is a GQM plan. The GQM plan is a document that contains the goals, questions and metrics for a measurement program (Solingen and Berghout 1999), in this case an ERP implementation project. The first phase of the study focuses on the definition of a set of metrics for user involvement and participation. The paper proceeds as follows. First, we present the research methodology used. Next, we present background in user involvement and participation and the GQM method. Then, we present the GQM plan proposed. Finally, we present some conclusions and further work.

\section{RESEARCH APPROACH}

As we have mentioned, we used the GQM method to develop a metrics plan. The steps of our research study were:

- Literature review related with user involvement and participation topic.

- Definition of goals related with user involvement and participation in ERP implementation projects.

- Definition of questions associated for each goal. 
- Definition of metrics associated to each question.

- Definition of the preliminary GQM plan.

A literature review of user involvement and participation topic and ERP implementations was made in order to acquire knowledge related with this CSF. The information provided by the literature review was our main source of knowledge. We used the concept of preliminary GQM plan due to the fact that any final GQM plan must be specific to the given real situation and thus validated by the project team that is going to use it. Here, we only provide a starting and thus tentative generic proposal for this plan.

\section{USER INVOLVEMENT AND PARTICIPATION BACKGROUND}

In the IS literature, the terms user involvement and user participation have frequently been used to mean the same thing. However, Barki and Hartwick $(1989,1994)$ claimed that the two concepts are different, and thus need to be defined separately:

- User involvement is defined to as "a psychological stage of the individual, and defined as the importance and personal relevance of a system to a user" (Hartwick and Barki 1994, p. 441), i.e., their attitude toward the development process and its product (the IS itself) while,

- User participation is defined as the observable behavior of users in the IS development and implementation, i.e., the set of operations and activities performed by users or their representatives during the IS development process (Hartwick and Barki 1994) or activities during the system implementation (Kappelman and McLean 1991).

Barki and Hartwick $(1989,1994)$ argued that the above interpretation of involvement would be consistent with how that term is used in the fields of psychology, marketing, and organizational behavior. Kappelman and McLean (1991) mention the term "user engagement" to include both user participation (the behavior) and user involvement (the attitude). Thus, according to their account, user engagement is "used to refer the total set of user relationships toward IS and their development".

\subsection{User Involvement}

Many reasons have been given to involve users in IS implementation projects. User involvement is predicted to increase user satisfaction and acceptance (Ives and Olson 1984) by: developing realistic expectations about system capabilities, providing an arena for bargaining and conflict resolution about design issues, leading to system ownership by users, decreasing user resistance to change, and committing users to the system. Kappelman and McLean (1991) suggested that user involvement is something distinct from, although associated with, user participation and, that the psychological state of user involvement may 
be more important than user participation in understanding IS success. An important aspect related with user involvement is 'user perceived control'. Baronas and Louis (1988, p. 114) stated that "by involving end-user in decisions relating to implementation, workers may become more invested in the success of the implementation and more satisfied with the system through the social-psychological mechanism of perceived control". 'Personal control' has been defined in terms of choice, predictability, responsibility and ability to reduce or get relief from an unpleasant condition. Baronas and Louis (1988) suggested that:

- Systems implementation is likely to be experienced by nontechnical users as a period of transition during which users make sense of, and cope with, various differences between old and new systems and their anticipations of these differences;

- Systems implementation is likely to represent a threat to user's perceptions of control over work.

Traditionally, the assumption in terms of user involvement is that if the organizational structure of an IS project is in place and appropriate committee meetings attended, their integration and coordination will occur. However, as Amoako and White (1997, p. 41) state "unlike the technical side of project management, these activities are very loosely defined, and very often include no mechanisms for the integration that will achieve the desired results". Therefore, there is the need for the distinction between structural integration and effective management of the involvement process. Characteristics such as user expertise, degree of organizational decentralization, project complexity, users' previous experience with IS could determine the degree of their involvement. Barki and Hartwick (1994) differentiated user involvement from other psychological states, particularly attitude. While the term user attitude "should be used to refer to a psychological state reflecting the affective or evaluative feelings concerning a new system" (Barki and Hartwick, p. 62), user involvement refers to "a belief - the extent to which a user believes that a new system is both important and personally relevant" (Barki and Hartwick, p. 62).

Kappelman (1995) divides user involvement in two types: user process involvement and user system involvement. User process involvement refers to the psychological identification of users with the process of IS development (i.e. their subjective attitude toward the IS development task). In addition, user system involvement refers to the psychological identification of users with respect to the IS itself (i.e. their subjective attitude toward the product of development).

\subsection{User Participation}

According to Briolat and Pogman (2000), "user participation is advocated in order to discover users' needs and points of view, validate specifications, and hence build better IS for the organization". Participation reflects what specific behaviors are performed, how many of 
these behaviors are performed, and how often they are performed (Barki and Hartwick 2001). The role of user participation in organizational activity can be viewed from the perspective of two different behavioral theories (Ives and Olson 1984). These theories are 'planned organizational change' and 'participative decision-making'. The implementation of a new IS often implies a planned change in the way that an organizational unit pursues its objectives. Participative decision making emphasizes the role of individuals in working groups. Ives and Olson (1984) also outlined how user participation (at that time they named it user involvement) can improve system quality by: providing a more and complete assessment of user information requirements, providing expertise about the organization the system is to support, avoiding development of unacceptable or unimportant features, and improving user understanding of the system. Mckeen and Guimarães (1994) showed that user participation has a positive relationship with user satisfaction. They also argued that four factors affect this relationship: task complexity, system complexity, user influence and user-developer communication. Barki and Hartwick (2001) define four dimensions of user participation:

- Responsibility - the performance of activities and assignments reflecting overall leadership or accountability for the project.

- User-IS relationship - the performance of development activities reflecting users' formal review, evaluation, and approval of work done by the IS staff.

- Hands-on-activity - the performance of specific physical design and implementation tasks.

- Communication activity - activities involving formal or informal exchanges of facts, needs, opinions, visions, and concerns regarding the project among the users and between users and other project stakeholders.

Based in a meta-analysis study, Pettingell et al. (1988) concluded that the inclusion of users in definition and design stages is the best way to increase their perception of the value of the system. Jiang et al. (2002) suggest that preproject partnering helps to involve users during the project and to motivate them in order to achieve project success. Preproject partnering refers to a work philosophy in which system stakeholders work together before the project begins (Cowan et al. 1992). The purpose of preproject partnering is to build a foundation among stakeholders for collaboration. In addition to identifying key stakeholders and their objectives, partnering emphasizes the activities of identifying potential conflict areas, providing a process for resolution of conflict, and incorporating a continuous improvement component in the project process. These results show the importance of involving users before the project starts and then in all the implementation phases. Figure 1 presents a summary of the constructs proposed by different authors for user involvement and participation. These constructs are be the basis for the development of our metrics program.

$<$ Introduce Figure n. 1 here $>$ 


\subsection{User Involvement/Participation in the ERP Implementation Context}

In this section we try to understand user involvement and participation in an ERP implementation context. We focus on why user involvement and participation is important and how it could be done. These are some of the main reasons to involve users: maximize user acceptance, improve system functionality, and improve ERP configuration. User involvement and participation provides with an intelligent function to the management of the project (Kawalek and Wood-Harper 2002). Organizations intending to implement an ERP system must be willing to dedicate some of their best employees to the project for a successful implementation (Bingi et al. 1999) who mention that these employees should not only be experts in the business processes of the organization but also be aware of the best business practices in the industry. They should exhibit the ability to understand the overall needs of the company and should play an important role in guiding the project efforts in the right direction. These employees can play different roles in the project. Some will integrate the project team, others will be key-users and some others will be end-users that will help in specific moments according to the project needs. As Baronas and Louis (1988) mentioned, users perceived IS implementations as a period of transition during which personal control is threatened. This aspect is often detected in ERP implementation projects since in most cases these implementations are associated to changes in their working routines. This threat may cause conflicts during the ERP implementation project and resistance to ERP system acceptance.

According to Amoako and White (1997), user involvement and participation management requires at least two forms of two-way communication: Communication between the various team members (inwards communication), and communication between the project team and the user or management groups (outwards communication). Not surprisingly, strong communication inwards and outwards as another CSF in ERP implementation projects (Esteves and Pastor 2000, Nah et al. 2001). This two-way communication must inform users of project changes that might affect their activities, and users must get adequate feedback on their concerns. It requires also telling and showing users that their input is valued, used and will be sought constantly, i.e. that they must be committed with the project. Amoako and White (1997) also suggest a set of guidelines in order to manage user involvement and participation. User participation deals with the topics related to the management of their time and activities within the organization, and managers must decide how much effort these users dedicate to their usual activities and to the project, and when they do both things. Most organizations cannot afford the effort of completely sacrificing these users towards ERP project needs. Some project managers also argue that the involvement and participation of users delays the accomplishment of task schedules. Therefore, and due to time pressures, most of them decide to avoid the use of users.

Esteves and Pastor (2001) studied the relevance of user involvement and participation along the phases of a specific SAP implementation project with the ASAP methodology and their 
conclusion is that user involvement and participation is more critical in design, realization and preparation phases. These are the phases where their know-how is very important to achieve a good fit of the ERP system to organizational needs. A detailed task where users must be especially involved is in the definition of forms and reports. Project team members must get end-user requirements, then customize forms and reports, and finally get user acceptance (Welti 1999). As Welti (1999) says, this is a time-consuming task but most of those documents represent the company image to the customer. He suggests that forms and reports should be discussed and settled with the user in the realization phase.

\subsection{User role-based concept and activities in ERP implementation projects}

In IS research much interest has been directed at the role of users in the development and implementation of IS. User roles are used to manage resources or skill sets as they pertain to tasks and deliverables that are done on projects. User roles can be thought of as the types of skill or people needed in order to complete a project. As Terry and Standing (2004) mention, the term "user" is open to ambiguity. Land and Hirschheim (1983) acknowledge the existence of different types of users: senior management who bear ultimate responsibility for the organisation's well-being and who may use outputs of IS developments; middle management who are responsible for the operational staff using the IS; and finally those staff who regularly interact with the system. From project conception, through the development lifecycle each of these users may contribute or participate in IS development activities. In order to understand the involvement and participation of users in ERP implementation projects, we analyzed a typical ERP implementation methodology. The objectives of this analysis were twofold. First, we attempted to identify the different user roles in a typical ERP implementation project. Second, we attempted to identify and analyze the different activities that users play in a typical ERP implementation. In this case, we used the Accelerated SAP methodology (ASAP) and its related processes.

ASAP is the implementation methodology that is used to perform a rapid implementation of the SAP R/3 system. The ASAP implementation methodology is structured in phases, work packages, activities and tasks. ASAP distributes all work packages across the individual phases according to activity areas and user roles. The user role-based concept ensures redundancy-free, goal-oriented work according to the task at hand and enables the synchronization of all activities. Table 1 represents the different stakeholder roles in a typical SAP implementation project and the five ASAP implementation phases. For each role, we quantified the number of work packages (wp) that role is defined as "involved" in each phase. In none of the phases end-users are directly expressed as needed, except the role of the business process owner. Power (or key) users are involved in all phases except on project preparation phase. The purpose of this phase is to provide initial planning and preparation of the SAP implementation project. The steps of this phase help identify and plan the primary focus areas to be considered such as: objectives, scope, plan and definition of project team. 
Both, business process owners and power users are more involved in the third and fourth phases, when the system is parameterized and tested, whereas in the second phase their role is to help in business process modeling and redesign.

$<$ Introduce Table n. 1 here $>$

Paradoxically, the lack of proposed direct involvement of end-users in ASAP implementation projects (especially in project preparation and business blueprint phases) contradicts the need to ensure that users participate in these tasks in order to improve user acceptance and to achieve project success. Usually, ERP implementation methodologies sound more worried with the system implementation and they presuppose that end-users will accept the ERP system. The rest should be provided by implementation consulting methodologies.

\section{A GQM PRELIMINARY PLAN FOR USER INVOLVEMENT AND PARTICIPATION ON ERP IMPLEMENTATIONS}

The measurement framework has been defined in terms of metrics, mechanisms of data collection, and guidelines to use the collected data. It has been defined on the basis of the GQM paradigm (Basili et al. 2004, Solingen and Berghout 1999) that considers a conceptual level, referred to the definition of the GOALS, an operational level, consisting of a set of QUESTIONS regarding the specific goals, and a quantitative level, identifying a set of METRICS to be associated to each QUESTION. We present below an overview of the GQM approach and then we describe each of the components of the GQM preliminary plan: measurement goals, questions and metrics. For the measurement goal defined, the following aspects are described: goal description and its refinement into questions, and finally, refinement from questions to metrics.

\subsection{GQM Method Overview}

The GQM approach is a mechanism that provides a framework for developing a metrics program. It was developed at the University of Maryland as a mechanism for formalizing the tasks of characterization, planning, construction, analysis, learning and feedback. GQM does not provide specific goals but rather a framework for stating measurement goals and refining them into questions to provide a specification for the data needed to help achieve the goals (Basili et al. 1994). The GQM method contains four phases: planning phase, definition phase, data collection phase and interpretation phase (for more details see Solingen and Berghout (1999)). The definition phase is the second phase of the GQM process and concerns all activities that should be performed to formally define a measurement program. By using a GQM a certain goal is defined, this goal is refined into questions, and, subsequently, metrics 
are defined that should provide the information to answer these questions. By answering the questions, the measured data can be analyzed to identify if the goals are attained.

One of the most important outcomes of this phase is the GQM plan. A GQM plan or GQM model documents the refinement of a precisely specified measurement goal via a set of questions into a set of metrics. Thus, a GQM plan documents which metrics are used to achieve a measurement goal and why these are used - the questions provide the rationale underlying the selection of the metrics.

\subsection{Goals of the GQM Preliminary Plan}

In our case of user involvement and participation, the definition of the measurement goals was made using the template provided by (Basili et al. 1994). A GQM goal is described according to a template with five dimensions that express the object to be measured, the purpose of measurement, the measured property of the object (quality focus), the subject of measurement (viewpoint), and the measurement's context (environment). We defined two measurement goals based in our CSF, user involvement and user participation (see table 2).

$<$ Introduce Table n. 2 here $>$

\subsection{Questions and Metrics}

For each measurement goal we defined a set of questions and related metrics (see table 3). To define these questions we made an extensive literature review on user involvement and participation topic (see background section). The questions of user participation measurement goal are based in the Hartwick and Barki (2001) survey. This survey has been used and validated in several IS research studies. We adapted this survey to the context of an ERP implementation project.

\section{$<$ Introduce Table n. 3 here $>$}

The questions (see table 4) for measurement goal two are related with user involvement and they arose from the literature review we made on the topic and especially on the instrument operationalized by Zaichowsky (1985) "personal involvement inventory". This instrument was developed "to measure a person's involvement with products" (Zaichowsky, 1985, p. 349). As suggested by Barki and Hartwick (1994), we eliminated the constructs related to user attitude, focusing only on user involvement constructs. With regard to Kappelman (1995) user process involvement and user product involvement constructs, since they are variations of the larger concept called user involvement, Kappelman used minor variations of Zaichowsky (1985) constructs. Thus, here we only present the questions for the general concept - user involvement. 
$<$ Introduce Table n. 4 here $>$

\title{
4.4 Metrics Identification
}

For each question, we defined metrics that answer the respective question. Table 5 and table 6 show the metrics and the respective relationship between the questions defined above and the metrics.

\author{
$<$ Introduce Table n. 5 here $>$ \\ $<$ Introduce Table n. 6 here $>$
}

For each metric we defined the following aspects: what they are measuring, when they must be measured, what possible values they could have, who will measure them, what medium is used for data collection. We created a special form for the metrics description. Most of the metrics proposed are direct measurements except the metrics related with percentages.

\section{TOWARDS A FRAMEWORK FOR MONITORING USER INVOLVEMENT AND PARTICIPATION}

Based on the literature review on user involvement and participation and ERP implementations, we propose a framework for monitoring user involvement and participation on ERP implementation projects (see figure 2). The framework takes into account the ERP implementation phases, user involvement and participation dimensions (see figure 1), and the different user roles in an ERP project. This framework is adapted from the framework proposed by Olson and Ives (1980) for specifying types of user involvement. In an ERP implementation project these user roles are quite well typified in the ERP implementation methodologies.

\section{$<$ Introduce Figure n. 2 here $>$}

We propose that user involvement and participation metrics should be interpreted taken into consideration three dimensions: user involvement and participation dimensions, ERP user roles and ERP implementation phases. Users play different roles and have different relevance along the ERP implementation according to their roles (Esteves and Pastor 2001). Hartwick and Barki (2001) analyzed the questions in terms of the different user roles in a project. They concluded that the role that users play on team was found to have a strong impact on overall participation, as well on each of the four participation dimensions. It is expected that users 
that are members of the project team have more participation than nonmembers, both overall and on each of the four dimensions. Users that become the project managers are expected to have more participation than members overall, but not similarly to other dimensions. For the responsibility dimension the difference between managers and team members was much greater than the difference observed for the other three dimensions.

The literature on user involvement and participation identifies diverse dimensions that should be taking into account for measuring and monitoring this CSF. Finally, previous research (e.g. Barki and Hartwick 1994, 2001; Kappelman 1995) has shown that the construct of user involvement and participation in the development/implementation of an IS must be measured at different stages of the process. Furthermore, Esteves and Pastor (2001) showed that user involvement and participation CSF relevance varies along the ERP implementation phases. For instance, according to Esteves and Pastor (2001), it is expected that key users involvement participation will be higher in design, realization and preparation phases.

Therefore, the metrics values are affected by the interrelation between these dimensions. We defined five types of users: top management, team members, key-users, IS personnel and endusers. Users can also be categorized by their different levels (Olson and Yves 1980): executive management (top level), operational management (middle level), supervisory personnel, and operating personnel. Although we did not mention before, other stakeholders like the ERP vendor play an important role in an ERP implementation project and it would be also desirable to analyze its involvement in the ERP implementation project. There is the evidence that some ERP projects failed in achieve good levels of all stakeholders. Regarding users activities, instead of defining them in another dimension as Olson and Ives (1980) framework, we consider them as part of the ERP implementation phases since all the ERP implementation methodologies provide a detailed explanation of work packages, activities and tasks by user role along the different ERP implementation phases.

\section{CONCLUSIONS AND FUTURE WORK}

This study presents a set of metrics for user involvement and participation in ERP implementation projects. User involvement and participation is cited as one of the most relevant critical success factors in ERP implementation projects. The set of metrics is based on the existent knowledge on user involvement and participation in IS field and ERP field in particular. This fact is very important since organizations do not have this internal knowledge previously to the ERP implementations. Thus, one of the contributions of this study is bringing to attention issues related with user involvement and participation that require management, yet may not normally be treated as important issues until they become critical. 
We think these metrics have two important proactive characteristics: metrics help to detect deviations from the project plan and to act before damage is made, and second, these metrics can have the effect of motivating and encouraging top managers in the involvement and commitment with the ERP project. The results of this work are twofold. First, a GQM plan to monitor and control ERP implementation projects is presented and second, a literature review on user involvement and participation on ERP implementation projects. The purpose of this study is not to describe an exhaustive list of metrics. Instead, we intend to present a form to develop these metrics in future ERP implementation projects and provided the first set of metrics that should be extended and adapted according to the specific needs of ERP implementation projects.

This study only provides the first step to propose a set of metrics for user involvement and participation, i.e., the definition of these metrics. Next steps are the metrics validation and interpretation. Two possible kinds of validation methods can be applied: case study or control experiments (Calero et al. 2001). We would like to remark that we accept that this GQM preliminary plan will be subject to changes during the next steps of the research due to new information gathered and experience gained in the feedback sessions. Another aspect is the importance of knowing the relevance of each CSF along the stages of an implementation project (Esteves and Pastor 2001) due to the fact that this information can help managers to know when they should put more attention to specific metrics in each stage. Currently, we are developing a software application for the management of the metrics defined here. Further research will attempt to define metrics for other CSF defined in the literature of ERP implementation projects. 


\section{REFERENCES}

Amoako, K. \& White, K. (1997). When is User Involvement not User Involvement? The Executive's Journal, 13(4), 40-46.

Bancroft, N., Seip H. \& Sprengel, A. (1998). "Implementing SAP R/3". Second edition, Manning Publications.

Barki, H. \& Hartwick, J. (1989). Rethinking the Concept of User Involvement. MIS Quarterly, 13(1), 53-63.

Barki, H. \& Hartwick, J. (1994). Measuring User Participation, User Involvement, and User Attitude. MIS Quarterly, 18(1), 59-82.

Barki, H. \& Hartwick, J. (2001). Communications as a Dimension of User Participation. IEEE Transactions on Professional Communication", 44(1), 21-35.

Baronas, A. \& Louis, M. (1988). Restoring a Sense of Control during Implementation: How User Involvement Leads to System Acceptance. MIS Quarterly, 12(1), 111-124.

Basili V., Caldera C. \& Rombach H. (1994). Goal Question Metric Paradigm, Encyclopedia of Software Engineering (Marciniak J. editor), vol. 1, John Wiley \& Sons, 528-532.

Bingi, P., Sharma, M., Godla, J., (1999). Critical Issues Affecting an ERP Implementation, Information Systems Management, 16(3), summer 1999.

Briolat, D. \& Pogman, J. (2000). User Involvement Influence on Project Productivity in a Rad Environment: a Quasi-experiment. European Software Control and Metrics Conference, Munich, April 2000.

Calero, C., Piattini, M. \& Genero, M. (2001). Method for Obtaining Correct Metrics. Third International Conference on Enterprise Information Systems, 779-784.

Cowan, C., Gray, C. \& Larson, L. (1992). Project Partnering. Project Management Journal, 22(4), 5-11.

Esteves, J. \& Pastor, J. (2000). Towards the Unification of Critical Success Factors for ERP Implementations. 10th Annual BIT conference, Manchester.

Esteves, J. \& Pastor, J. (2001). Analysis of Critical Success Factors Relevance along SAP Implementation Phases. Americas Conference on Information Systems, Boston.

Hartwick, J. \& Barki, H. (1994). Explaining the Role of User Participation in Information System Use. Management Science, 40(4), 440-465

Ives, B. \& Olson, M. (1984). User Involvement and MIS Success: A Review of Research. Management Science, 30(5), 586-603.

Jiang, J., Chen, E. \& Klein, G. (2002). The Importance of Building a Foundation for User Involvement in Information System Projects, Project Management Journal, 33(1), 20-26.

Jurison, J. (1999). Software Project Management: The Manager's View. Communications of the Association for Information Systems, 2(17), September 1999.

Kale, V. (2000). Implementing SAP R/3: The Guide for Business and Technology Managers. Sams Publishing. 
Kappelman, L., \& McLean, E. (1991). The Respective Roles of User Participation and User Involvement in Information Systems Implementation Success. International conference on information systems, New York, 339-348.

Kappelman, L. (1995). Measuring User Involvement: A Diffusion of Innovation Perspective. The Data Base for Advances in Information Systems, 26(2/3), 65-86.

Kawalek, P. \& Wood-Harper, T. (2002). The Finding of Thorns: User participation in Enterprise System Implementation. The Data Base for advances in information systems, 33(1), 13-22.

Land, F. \& Hirschheim, R. (1983). Participative systems design: Rationale, tools and techniques. Journal of Applied Systems Analysis, 10, 91-107.

Mckeen, J. \& Guimarães, T. (1994). The Relationship between User Participation and User Satisfaction: An Investigation of Four Contingency Factors. MIS Quarterly, 18(4), 427452.

Nah, F., Lau, J., \& Kuang, J. (2001). Critical Factors for Successful Implementation of Enterprise Systems. Business Process Management Journal, 7(3), 285-296.

Olson M. \& Ives B. (1980). Measuring User Involvement in Information System Development. International Conference on Information Systems, pp. 130-143.

Pettingell, K., Marshall T. \& Remington W. (1988). A Review of the Influence of User Involvement on System Success. 9th International Conference on Information Systems.

Solingen, R. \& Berghout, E. (1999). The Goals/Question/Metric Method: A Practical Guide for Quality Improvement of Software Development. McGraw-Hill.

Terry, J. \& Standing, C. (2004). The Value of User Participation in E-Commerce Systems Development. Inform Science Journal, 7, 31-45.

Welti, N. (1999). Successful SAP R/3 Implementation: Practical Management of ERP Projects. Addison-Wesley.

Zaichowsky, J. (1985). Measuring the Involvement Construct. Journal of Consumer Research, 12, 341-352. 


\section{FIGURES}

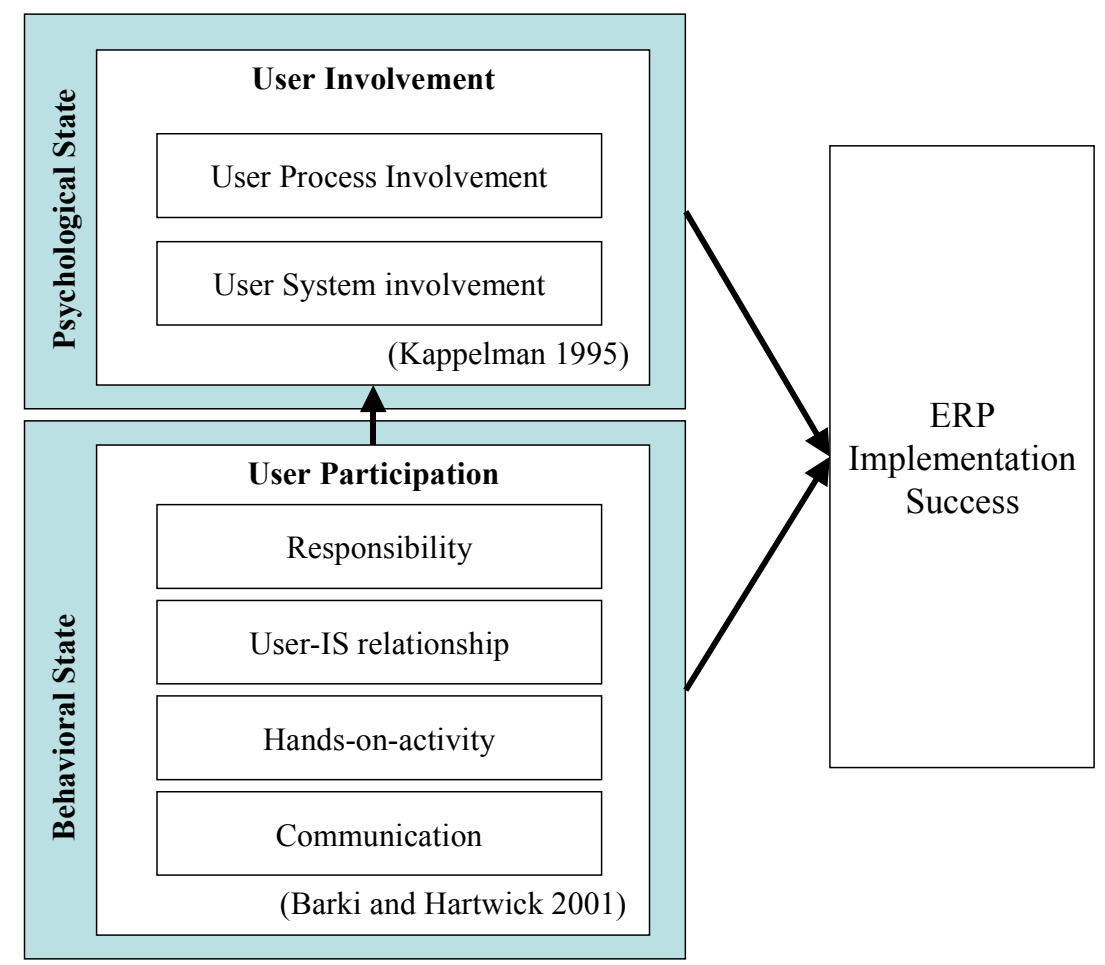

Figure 1 - Constructs proposed by different authors for user involvement and participation.

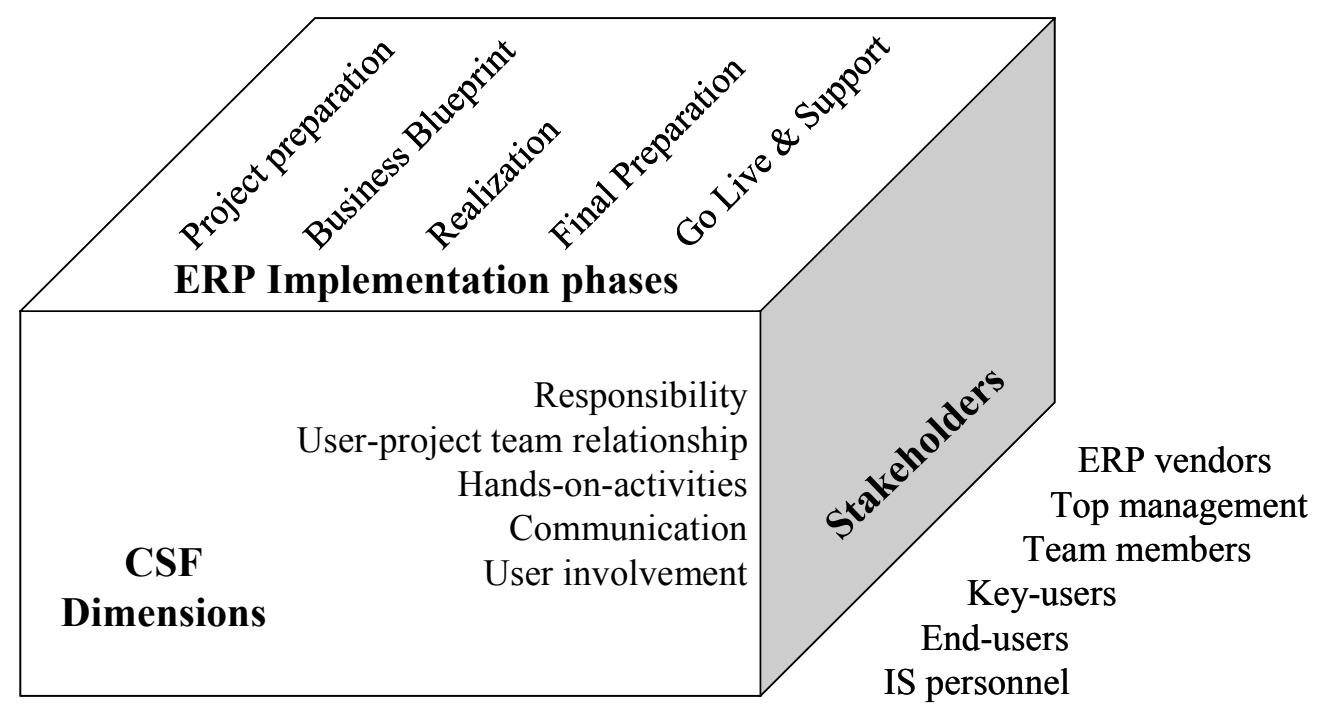

Figure 2 - A Framework for monitoring user involvement and participation in ERP implementation projects. 


\section{TABLES}

\begin{tabular}{|c|c|c|c|c|c|}
\hline SAP implementation project roles & 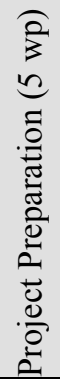 & 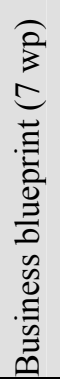 & 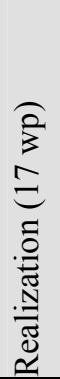 & 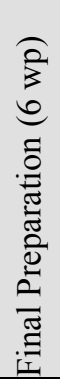 & $\begin{array}{l}2 \\
3 \\
2 \\
0 \\
0 \\
.3 \\
0 \\
\infty \\
0 \\
0\end{array}$ \\
\hline Project manager & \multirow{13}{*}{$\begin{array}{l}4 \\
2 \\
2 \\
2 \\
3 \\
4\end{array}$} & 6 & 11 & 5 & 2 \\
\hline Project sponsor & & 2 & 2 & 1 & \multirow[t]{2}{*}{2} \\
\hline Steering committee & & 3 & 4 & 1 & \\
\hline Project team & & 2 & 7 & 3 & 1 \\
\hline Business team leader & & 4 & 13 & 4 & \multirow[t]{2}{*}{1} \\
\hline Technical team leader & & 4 & 11 & 5 & \\
\hline Consultants & & 4 & 11 & 4 & \multirow[t]{2}{*}{1} \\
\hline IT professional (different functions) & & \multirow[t]{2}{*}{2} & \multirow[t]{2}{*}{11} & \multirow[t]{2}{*}{2} & \\
\hline End-user & & & & & \multirow{5}{*}{1} \\
\hline Key user & & 1 & 7 & 3 & \\
\hline Business process owner & & 1 & 8 & 1 & \\
\hline Key site sponsors & & 1 & 1 & & \\
\hline Line manager & & 1 & & & \\
\hline Core change team & \multirow[t]{6}{*}{3} & 3 & 2 & 1 & 1 \\
\hline Extended core change team & & 2 & 1 & & 1 \\
\hline Project risk manager & & & & & \\
\hline ABAP developer & & & 4 & & \\
\hline Development manager & & & 4 & & \\
\hline SAP reviewer & & 2 & 1 & 1 & 1 \\
\hline SAP project manager & \multirow[t]{3}{*}{2} & & & & \\
\hline Help desk provider & & & 1 & 1 & 1 \\
\hline Documentation and training developers & & & 1 & 1 & \\
\hline
\end{tabular}

Table 1 - Roles used along a SAP implementation project. 
Goal 1

\begin{tabular}{|l|l|}
\hline Analyze: & User participation \\
\hline For the purpose of & Monitoring \\
\hline With respect to & ERP implementation project \\
\hline From the viewpoint of & Project Team \\
\hline In the context of & ERP implementation project \\
\hline
\end{tabular}

Goal 2

\begin{tabular}{|l|l|}
\hline Analyze: & User involvement \\
\hline For the purpose of & Monitoring \\
\hline With respect to & ERP implementation project \\
\hline From the viewpoint of & Project Team \\
\hline In the context of & ERP implementation project \\
\hline
\end{tabular}

Table 2 - Goals for user involvement and user participation.

\begin{tabular}{|c|c|}
\hline & Questions \\
\hline Responsibility & $\begin{array}{l}\text { 1. How much responsibility did users have for estimating project and systems costs? } \\
\text { 2. How much responsibility did you have for requesting additional funds to cover } \\
\text { unforeseen time/costs overruns? } \\
\text { 3. How much responsibility did you have for managing the project (e.g. staffing the } \\
\text { 4. How much responsibility did you have for overall success of the project and the } \\
\text { system? } \\
\text { 5. How much responsibility did you have for initiating the project? } \\
\text { 7. How much responsibility did you have for determining system objectives? } \\
\text { 8. How much responsibility did you have for estimating project and system benefits? } \\
\text { 9. How many of these behaviors are performed? } \\
\text { 10. How often they are performed? }\end{array}$ \\
\hline $\begin{array}{l}\text { User-project team } \\
\text { relationship }\end{array}$ & $\begin{array}{l}\text { 11. Did the project team draw up a formal agreement of work to be done during the } \\
\text { project? } \\
\text { 12. Were you able to make changes to the formal agreement concerning work to be done } \\
\text { by the project team during the project? } \\
\text { 13. Did you sign off the formal agreement concerning work to be done by the project team } \\
\text { during the project? } \\
\text { 14. Did you formally evaluate an information requirements analysis developed by the } \\
\text { project team concerning the system? } \\
\text { 15. Did you formally review work done by the project team concerning the system? } \\
\text { 16. Did you formally accept and sign off work done by the project team concerning the } \\
\text { system? } \\
\text { 17. Did you formally review an information requirements analysis developed by the project } \\
\text { team concerning the system? } \\
\text { 18. Did you formally evaluate work done by project team concerning the system? } \\
\text { 19. Did you approve project timetables? } \\
\text { 20. Did you prepare project progress reports? }\end{array}$ \\
\hline
\end{tabular}




\begin{tabular}{|c|c|}
\hline $\begin{array}{l}\text { Hands-on } \\
\text { activities }\end{array}$ & $\begin{array}{l}\text { 21. Did you [design; help to design; have nothing to do with designing] input/output } \\
\text { forms? } \\
\text { 22. Did you [design; help to design; have nothing to do with designing] screen layouts? } \\
\text { 23. Did you [design; help to design; have nothing to do with designing] report formats? } \\
\text { 24. Did you [prepare; help prepare; have nothing to do with preparing] users manuals? } \\
\text { 25. Did you [design; help to design; have nothing to do with designing] the user-training } \\
\text { program? } \\
\text { 26. Did you [train; help train; have nothing to do with training] other users to use the } \\
\text { system? } \\
\text { 27. Did you [design; help to design; have nothing to do with designing] system security } \\
\text { procedures? } \\
\text { 28. Did you [set; help set; have nothing to do with setting] system access priorities? } \\
\text { 29. Did you [determine; help determine; have nothing to do with determining] data access } \\
\text { privileges? } \\
\text { 30. Did you participate in testing activities? }\end{array}$ \\
\hline $\begin{array}{l}\text { Communication } \\
\text { activities }\end{array}$ & $\begin{array}{l}\text { 31. How often did you communicate informally with other users concerning the project? } \\
\text { 32. How often did you exchange facts, opinions, and visions concerning the project with } \\
\text { other users? } \\
\text { 33. How often did you discuss your reservations and concerns regarding the project with } \\
\text { other users? } \\
\text { 34. How often did your communicate informally with the project team concerning the } \\
\text { project? } \\
\text { 35. How often did you exchange facts, opinions, and visions concerning the project with } \\
\text { project team? } \\
\text { 36. How often did you discuss your reservations and concerns regarding the project with } \\
\text { the project team? } \\
\text { 37. How often did the project team discuss their reservations and concerns regarding the } \\
\text { project with you? } \\
\text { 38. How often did you communicate informally with senior management concerning the } \\
\text { project? } \\
\text { 39. How often did you exchange facts, opinions, and visions concerning the project with } \\
\text { senior management? } \\
\text { 40. How often did you discuss your reservations and concerns regarding the project with } \\
\text { senior management? }\end{array}$ \\
\hline
\end{tabular}

Table 3 - Questions for user participation goal.

\begin{tabular}{|l|l|}
\hline & Questions \\
\hline User & 42. Did you think that the ERP systems was essential for your work? \\
Involvement & 43. Did you think that the ERP system was trivial? \\
& 44. What was the level of the ERP system significance? \\
& 45. did you think that the ERP system was important for you? \\
& 46. Did you think that you needed the ERP system to perform your job? \\
& 47. What was the level of the ERP system relevance to you? \\
& 48. Did you think that the ERP concerns to you? \\
\hline
\end{tabular}


49. Did the ERP system matter to you?

50. Did the ERP system mean something to you?

51. Did you feel excited with the ERP system?

52. What is the level of the ERP system interest to you?

Table 4 - Questions for user involvement goal.

\begin{tabular}{|c|c|c|}
\hline Dimension & Metrics & Questions \\
\hline \multirow{10}{*}{ Responsibility } & Responsibility for project estimation & 1 \\
\hline & Responsibility for estimating costs & 1 \\
\hline & $\begin{array}{l}\text { Responsibility for requesting additional funds to cover unforeseen time/costs } \\
\text { overruns }\end{array}$ & 2 \\
\hline & Responsibility for managing the project & 3 \\
\hline & Responsibility for overall success of the project & 4 \\
\hline & Responsibility for initiating the project & 5 \\
\hline & Responsibility for determining system objectives & 6 \\
\hline & Responsibility for estimating project and systems benefits & 7 \\
\hline & Types of behaviors performed & 8,9 \\
\hline & Estimated duration of behavior & 10 \\
\hline \multirow{7}{*}{$\begin{array}{l}\text { User-project } \\
\text { team } \\
\text { relationship }\end{array}$} & User's participation in project plan & 11 \\
\hline & Changes made by users to project plan & 12 \\
\hline & Participation in project sign off & 13 \\
\hline & Participation in evaluation of information requirements analysis & 14 \\
\hline & Participation in sign off of information requirements analysis & 16 \\
\hline & Participation in review meetings & $17,18,19$ \\
\hline & Participation in support meetings & 15,20 \\
\hline \multirow{10}{*}{$\begin{array}{l}\text { Hands-on } \\
\text { activities }\end{array}$} & Participation in forms design & 21 \\
\hline & Participation in screens layout & 22 \\
\hline & Participation in reports format & 23 \\
\hline & Participation in user manuals preparation & 24 \\
\hline & Participation in training plan & 25 \\
\hline & Participation as trainer & 26 \\
\hline & Participation in systems security procedures & 27 \\
\hline & Participation in system access priorities & 28 \\
\hline & Participation in data access privileges & 29 \\
\hline & Participation in testing activities & 30 \\
\hline \multirow{3}{*}{$\begin{array}{l}\text { Communication } \\
\text { activities }\end{array}$} & Communication between users & $31,32,33$ \\
\hline & Communication between users and project team & $34,35,36,37$ \\
\hline & Communication with senior managers & $38,39,40,41$ \\
\hline
\end{tabular}

Table 5 - The set of metrics for user participation goal. 


\begin{tabular}{|l|l|l|}
\hline \multicolumn{1}{|c|}{ Dimension } & \multicolumn{1}{|c|}{ Metrics } & Questions \\
\hline \multirow{4}{*}{$\begin{array}{l}\text { User } \\
\text { involvement }\end{array}$} & Essential & 42 \\
\cline { 2 - 3 } & Trivial & 43 \\
\cline { 2 - 3 } & Significance & 44 \\
\cline { 2 - 3 } & Importance & 45 \\
\cline { 2 - 3 } & Necessary & 46 \\
\cline { 2 - 3 } & Relevance & 47 \\
\cline { 2 - 3 } & Concerns & 48 \\
\cline { 2 - 3 } & Matters & 49 \\
\cline { 2 - 3 } & Means & 50 \\
\cline { 2 - 3 } & Excitement & 51 \\
\cline { 2 - 3 } & Interest & 52 \\
\hline
\end{tabular}

Table 6 - The set of metrics for user involvement goal. 
NOTAS

בx


NOTAS

בx


NOTAS 